
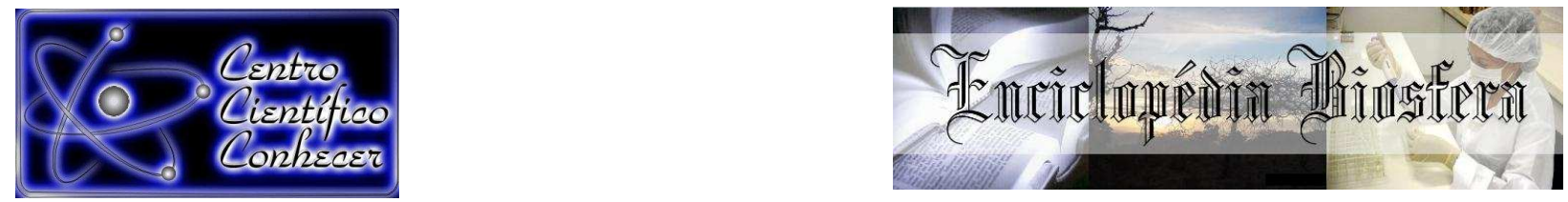

\title{
PRODUÇÃO DE PECTINA LIASE POR LINHAGENS DE FUNGOS FILAMENTOSOS EM POLPAS DE BURITI E MARACUJÁ COMO FONTES DE CARBONO
}

Tiago Nunes Farias ${ }^{1}$, Ilio Fealho de Carvalho ${ }^{2}$, Fabiano de Paula Pereira Machado ${ }^{3}$, Nilo Leal Sander ${ }^{4}$, Carolina Joana da Silva ${ }^{5}$

${ }^{1}$ Graduando em Ciências Biológicas, Universidade do Estado de Mato Grosso (UNEMAT), Tangará da Serra - MT, Brasil. E-mail: thyaggofarias@hotmail.com.

${ }^{2}$ Professor Doutor do Departamento de Ciências Biológicas, Universidade do Estado de Mato Grosso (UNEMAT), Tangará da Serra - MT, Brasil.

${ }^{3}$ Professor Doutor do Departamento de Engenharia de Alimentos, Universidade do

Estado de Mato Grosso (UNEMAT), Barra do Bugres - MT, Brasil.

${ }^{4}$ Doutorando em Biodiversidade e Biotecnologia da Amazônia Legal, Rede

BIONORTE, Laboratório de Ecologia da Paisagem - CELBE, Universidade do

Estado de Mato Grosso (UNEMAT), Cáceres - MT, Brasil.

${ }^{5}$ Departamento de Ciências Biológicas, Centro de Pesquisa em Limnologia,

Biodiversidade e Etnobiologia do Pantanal/Rede BIONORTE, Universidade do

Estado de Mato Grosso (UNEMAT), Cáceres - MT, Brasil.

Recebido em: 08/09/2015 - Aprovado em: 14/11/2015 - Publicado em: 01/12/2015

DOI: http://dx.doi.org/10.18677/Enciclopedia_Biosfera_2015_026

\begin{abstract}
RESUMO
Atualmente, a utilização de resíduos agroindustriais na produção de enzimas tem sido amplamente avaliada por se tratar de uma fonte renovável de baixo custo. Subprodutos como polpa de maracujá possuem alto teor de pectina, servindo de indutor de pectina liase. Os objetivos desse trabalho foram avaliar a produção de pectina liase por linhagens de fungos filamentos isolados do vale do Guaporé na Amazônia Meridional, utilizando polpa de maracujá e de buriti como fontes de carbono, e avaliar as propriedades bioquímicas ( $\mathrm{pH}$ e temperatura) do extrato enzimático bruto. As linhagens de fungos foram pré-selecionadas com base na formação do halo de degradação do ácido galacturônico pelas pectinases. Dentre as linhagens pré-selecionadas a linhagem 2 apresentou maior atividade enzimática com 8,94 U. $\mathrm{mL}^{-1}$ de pectina liase na presença de polpa de buriti como fonte indutora. A pectina liase apresentou maior atividade na faixa de 40 a $70{ }^{\circ} \mathrm{C}$ para ambos os substratos. Valores de $\mathrm{pH}$ na faixa de 3 a 4 foram mais apropriados para a hidrólise de pectina liase proveniente de polpa de maracujá, e, na faixa de $\mathrm{pH} 4$ a 6 para polpa de buriti, atingindo valores de atividade enzimática variando de 2,00 a 0,76 U. $\mathrm{mL}^{-1}$ para esses substratos, respectivamente. A pectina liase apresentou perda de atividade após 30 minutos de incubação na faixa de 40 a $70{ }^{\circ} \mathrm{C}$. Constatou-se que as linhagens 2, 17 e 10 apresentaram um potencial para a produção da pectina liase e as fontes avaliadas induziram a produção dessa enzima.
\end{abstract}

PALAVRAS-CHAVE: Pectinase, Polpa de buriti, Polpa de maracujá. 


\title{
PECTIN LYASE PRODUCTION FROM FILAMENTOUS FUNGI STRAINS IN BURITI AND PASSION FRUIT PULP AS CARBON SOURCES
}

\begin{abstract}
Currently, the use of agro-industrial waste in the production of enzymes has been widely evaluated because it is a renewable source of low cost. Byproducts such as passion fruit pulp have high pectin content, which may be used as pectin lyase inductor. The objective of the current work was to evaluate the pectin lyase production by filamentous fungi strains isolated from the Vale do Guaporé, Amazônia Meridional, using passion fruit and buriti pulp as sources of carbon, and to determine the biochemical properties ( $\mathrm{pH}$ and temperature) of crude enzyme extract. The fungi strains were pre-selected based on the formation of galacturonic acid degradation halo by pectinases. Among the pre-selected strains, strain 2 showed higher enzyme activity with $8.94 \mathrm{U} \cdot \mathrm{mL}^{-1}$ pectin lyase in buriti pulp as an inducer source. The pectin lyase showed greater activity in the range 40 to $70^{\circ} \mathrm{C}$ for both substrates. Values of in the $\mathrm{pH}$ range of 3 to 4 were more suitable for the pectin lyase hydrolysis from passion fruit pulp, and at $\mathrm{pH} 4$ to 6 for buriti pulp, reaching enzymatic activity values ranging from 2,00 to $0,76 \mathrm{U} \cdot \mathrm{mL}^{-1}$ to those substrates respectively. The pectin lyase presented loss of activity after 30 minutes in the range of 40 to $70{ }^{\circ} \mathrm{C}$. It was found that the strains 2, 17 and 10 showed potential for the pectin lyase production and both sources studied was able to induce the enzymatic production.
\end{abstract}

KEYWORDS: Pectinase, Buriti pulp residue, Passion fruit pulp.

\section{INTRODUÇÃO}

Pectinases são enzimas que catalisam a hidrólise de substâncias pécticas presentes nas células vegetais, correspondendo a cerca de um quinto do mercado mundial de enzimas (CAMARGO et al., 2005; UENOJO \& PASTORE, 2007). Essas enzimas podem ser sintetizadas por diversos grupos de organismos, incluindo fungos filamentosos, plantas, bactérias, leveduras entre outros (SIROTEK et al., 2001; SANTI et al. 2014). Porém, predominam estudos relacionados à produção de pectinases produzidas por fungos filamentosos, visto que a maioria das enzimas utilizadas comercialmente são provenientes destes micro-organismos (SANTI et al., 2014).

As aplicações de pectinases são diversas, podendo ser utilizadas em indústrias de alimentos, na fermentação de chá, café e cacau, na extração de óleos vegetais, no processamento de vinhos, na estratificação e clarificação de sucos de frutas para aumentar a eficiência de filtração e na indústria têxtil e de papel, principalmente no tratamento e degomagem de fibras naturais (CAMARGO et al., 2005; UENOJO \& PASTORE, 2007).

As pectinases podem ser subdivididas em grupos com base na especificidade ao substrato e no mecanismo de catálise. As despolimerases (pectina liase-PL, poligalacturonase-PG e pectato liase-PAL) clivam a molécula de pectina entre os monômeros de ácido galacturônico, tanto por hidrólise (PG) quanto por $\beta$-eliminação (PL, PAL); a pectinesterase, catalisa a desesterificação, removendo os grupos metoxil da pectina (MARTOS et al., 2013). De modo geral, as enzimas despolimerizantes reduzem a viscosidade de soluções, enquanto as desesterificantes atuam principalmente sobre a pectina de alta metoxilação, sendo, portanto, indispensável para a ação das outras pectinases despolimerases (SANTI et al., 2014). Entretanto, dentre as enzimas pectinolíticas, a pectina liase é a única capaz de degradar uma molécula de pectina altamente ramificada sem o auxílio 
prévio de pectinesterase (CAMARGO et al., 2005). O mecanismo de catálise se baseia na atividade sobre o esqueleto galacturônico, sendo as exoenzimas responsáveis pela clivagem nas extremidades da cadeia, liberando dímeros ou monômeros, e as endoenzimas atuam de maneira randômica em regiões internas da pectina, liberando moléculas de tamanho intermediário (UENOJO \& PASTORE, 2007).

Atualmente, a necessidade de utilização de fontes de baixo custo para a produção de enzimas de interesse industrial tem aumentado. Neste sentido, diversos resíduos têm sido estudados - principalmente aqueles gerados a partir de frutas cítricas, como polpa de laranja, além de polpa de maracujá e de uva - visando à redução do custo de produção de enzimas (OLIVEIRA et al., 2011; IRSHAD et al., 2014; KOSER et al., 2014; GERHARDT et al., 2015). Em relação às pectinases, objetiva-se utilizar subprodutos que contenham pectina, servindo como fontes indutoras de baixo custo (IRSHAD et al., 2014; KOSER et al., 2014).

Como alternativa pode-se mencionar o fruto de buriti (Mauritia flexuosa), uma palmeira típica de ambientes úmidos. Seus frutos são ricos em vitaminas $A, B, C, E$, fibras, óleos insaturados e ferro, sendo amplamente utilizados na fabricação de doces, sucos e óleo. Dessa forma, essa frutífera pode ser considerada uma alternativa à essa demanda, visto que possui ampla ocorrência na Amazônia, Cerrado e Pantanal (SAMPAIO, 2011).

Portanto, o presente estudo teve por objetivo avaliar a produção de pectina liase por linhagens de fungos filamentos isolados do vale do Guaporé, Amazônia Meridional, utilizando polpas de buriti e maracujá como fontes de carbono indutoras, assim como avaliar as propriedades bioquímicas ( $\mathrm{pH}$ e temperatura) do extrato enzimático bruto.

\section{MATERIAL E MÉTODOS}

Os fungos filamentosos utilizados neste estudo foram isolados de amostras de solo da região da Amazônia Meridional coletadas às margens do Rio Guaporé, localizada no município de Vila Bela da Santíssima Trindade/MT/Brasil a $540 \mathrm{~km}$ da capital Cuiabá (1500'14,9"S e 5957'22,0"W). Os ex perimentos foram desenvolvidos no Laboratório de Microbiologia/CPEDA do Campus Tangará da Serra da Universidade do Estado do Mato Grosso (UNEMAT).

$O$ isolamento dos fungos a partir das amostras de solo foi realizado por meio da técnica de diluição seriada (SILVA et al., 2010). Para a ativação do complexo pectinolítico as linhagens foram cultivadas em meio contendo $1,25 \%$ de pectina, incubadas a $28{ }^{\circ} \mathrm{C}$ por um período de três dias. Para a seleção, as linhagens pectinolíticas foram inoculadas em placas contendo meio de cultura com $0,625 \%$ de ácido poligalacturônico e incubadas a $28{ }^{\circ} \mathrm{C}$ durante três dias. Para a revelação do halo de hidrólise do ácido poligalacturônico adicionou-se nas placas de Petri uma solução de vermelho rutênio 0,02\%, ficando imersas por 30 min e depois lavadas com água destilada estéril. A medida do halo de degradação foi expressa como a diferença entre o halo total subtraído pelo halo da colônia (UENOJO \& PASTORE, 2006). Foram selecionados os isolados de fungos que apresentaram diâmetro do halo de degradação igual ou superior a $1,40 \mathrm{~cm}$.

Os maracujás (Passiflora edulis $f$. flavicarpa Deg.) foram obtidos de indústria de processamento de frutas. Já os frutos do buriti foram coletados no município de Vila Bela da Santíssima Trindade, às margens do Rio Guaporé e trazidos ao Laboratório de Microbiologia da UNEMAT, onde foram selecionados e higienizados com água corrente. Para a extração da polpa, os frutos de buriti foram colocados de 
molho em água de torneira por um período de $24 \mathrm{~h}$, após, a casca foi removida por raspagem, assim como a polpa (SAMPAIO, 2011). Ambas as fontes de carbono foram lavadas duas vezes com água destilada, secas em estufa com circulação de ar a $50{ }^{\circ} \mathrm{C}$ por $48 \mathrm{~h}$ e os materiais secos foram trit urados em liquidificador $\mathrm{e}$ peneirados em Tamis de 60 mesh.

As linhagens pré-selecionadas através da técnica do halo de degradação foram cultivadas em frascos contendo $\left(\mathrm{NH}_{4}\right)_{2} \mathrm{SO}_{2} \quad 0,1 \%, \mathrm{~K}_{2} \mathrm{HPO}_{4}$ e $\mathrm{KH}_{2} \mathrm{PO}_{4} \quad 0,09 \%$, $\mathrm{MgSO}_{4}$ 0,01\%, pH 5,0 e 10,0 g. $\mathrm{L}^{-1}$ da fonte de carbono polpa de maracujá, polpa de buriti e pectina cítrica (controle) para avaliar a produção de pectina liase. Os frascos foram inoculados com $2 \mathrm{~mL}$ de uma suspensão contendo $1 \times 10^{7}$ esporos. $\mathrm{mL}^{-1}$ e incubados em agitador tipo shaker a $28{ }^{\circ} \mathrm{C}, 125 \mathrm{rpm}$ por um período de $96 \mathrm{~h}$. Após, 0 caldo de cultivo foi filtrado em papel Whatman® $\mathrm{n}$. 1 com auxílio de bomba a vácuo.

Para a determinação da atividade de pectina liase, primeiramente realizou-se a incubação da enzima. Para isso, adicionou-se $10,0 \mathrm{~mL}$ do extrato bruto e $10,0 \mathrm{~mL}$ de uma solução de pectina cítrica (Sigma) 0,5\% pH5 em tampão acetato de sódio $0,05 \mathrm{M} \mathrm{pH} 4,5 \mathrm{em}$ Erlenmeyer de $125 \mathrm{~mL}$ e incubou-se em banho-maria a $40{ }^{\circ} \mathrm{C}$ por $90 \mathrm{~min}$ (SANTI, 2005). Alíquotas de $3,0 \mathrm{~mL}$ foram retiradas nos tempos de 30 e 60 min e transferidas para três tubos de ensaio para dosagem. Em cada tubo de ensaio foram pipetados $1 \mathrm{~mL}$ dessa mistura e $1,75 \mathrm{~mL}$ de $\mathrm{HCl} 0,5 \mathrm{M}$. A absorbância foi medida em espectrofotômetro em comprimento de onda de $235 \mathrm{~nm}$ contra o branco (ALBERSHEIM \& KILLIAS, 1962). O coeficiente de extinção molar utilizado para cálculo foi $\varepsilon_{235 \mathrm{~nm}}=5550 \mathrm{M}^{-1} \mathrm{~cm}^{-1}$ (UENOJO \& PASTORE, 2006). Considerou-se uma Unidade enzimática $(U)$ como a quantidade de enzima necessária para produzir 1 $\mu \mathrm{mol}$ de ácido galactourônico $\mathrm{mL}^{-1} \cdot \mathrm{min}^{-1}$ nas condições do ensaio $\left(U=\mu \mathrm{mol} \cdot \mathrm{mL}^{-}\right.$ $\left.{ }^{1} \cdot \mathrm{min}^{-1}\right)$.

Para concentração da enzima, o extrato enzimático foi adicionado de acetona a frio $\left(-16{ }^{\circ} \mathrm{C}\right)$ na proporção de $(1: 3 \mathrm{v} / \mathrm{v})$ e colocad o a geladeira a $4{ }^{\circ} \mathrm{C}$ por $30 \mathrm{~min}$. Após, a mistura foi centrifugada a $3.200 \mathrm{rpm}$ a $4{ }^{\circ} \mathrm{C}$ por $20 \mathrm{~min}$. $\mathrm{O}$ sobrenadante foi descartado e o precipitado foi ressuspenso em água destilada estéril. A mistura foi saturada com sulfato de amônio $70 \%$ e deixado em repouso por $12 \mathrm{~h}$ a $4{ }^{\circ} \mathrm{C}$, seguido de centrifugação a $3.200 \mathrm{rpm}$ a $4{ }^{\circ} \mathrm{C}$ por $20 \mathrm{~min}$. $\mathrm{O}$ p recipitado foi ressuspenso em água destilada e dialisado contra água destilada gelada por $12 \mathrm{~h}$.

Para a determinação das propriedades bioquímicas: o $\mathrm{pH}$ - incubou-se a suspensão por 30 minutos em banho maria nos pHs: 3,0, 4,0, 5,0, 6,0, 7,0 e 8,0; a determinação da temperatura ótima de hidrólise fez-se por meio da incubação da suspensão nas temperaturas de $40,50,60,70$ e $80^{\circ} \mathrm{C}$ por 30 minutos em banho maria. A termoestabilidade foi realizada incubando-se o extrato enzimático bruto nas temperaturas de 40, 50, 60 e $70^{\circ} \mathrm{C}$. As dosagens for am realizadas retirando-se alíquotas para dosagem nos tempos de 30,60, 90, 120 e 150 minutos.

\section{RESULTADOS E DISCUSSÃO}

Dentre as linhagens cultivadas na presença das fontes de carbono e avaliadas para produção de pectina liase, a linhagem 2 mostrou-se mais promissora na presença de polpa de buriti, com produção enzimática de $8,94 \mathrm{U} \cdot \mathrm{mL}^{-1}$, enquanto a linhagem 10 na presença de polpa de maracujá produziu $7,00 \mathrm{U} \cdot \mathrm{mL}^{-1}$. A fonte de carbono controle (pectina cítrica) não demonstrou ser um bom indutor para a produção de pectina liase para os isolados como foram polpa de maracujá e polpa de buriti (Figura 1).

Utilizando bagaço de laranja (composto de casca, polpa e semente) para a indução de pectina liase por Aspergillus sp., CAMARGO et al. (2005) identificaram 
níveis de atividades de 11,30 U. $\mathrm{mL}^{-1}$. Essa diferença de atividade encontrada neste estudo quando comparada àquele apresentado por CAMARGO et al. (2005) pode ser atribuída ao fato de que linhagens de Aspergillus serem consagradamente boas produtoras de pectinases. Segundo BUENO et al. (2005) a produção dessas enzimas para fins industriais é feita principalmente por Aspergillus niger, entretanto, os níveis de atividades enzimáticas dependem das fontes de carbono utilizadas na produção. No presente estudo, a fonte de carbono polpa de buriti mostrou ser boa indutora de pectina liase para as linhagens 2 e 17 (Figura 1).

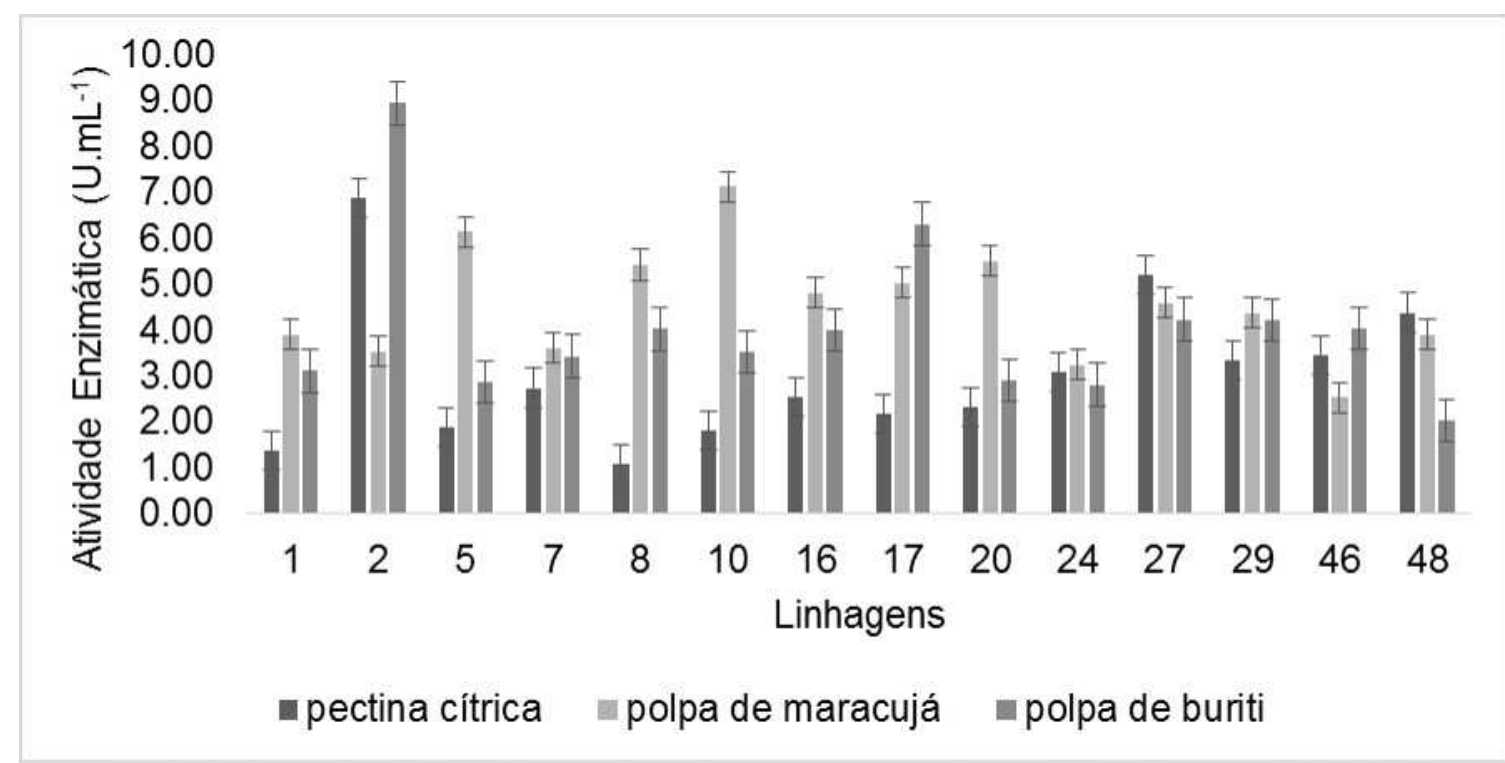

Figura 1 - Cultivo das linhagens de fungos em pectina cítrica (controle), polpa de maracujá e polpa de buriti como fontes indutoras à produção de pectina liase.

Alguns estudos (FRIEDRICH et al., 1994; PATIL \& DAYANAND, 2006) mostraram valores parecidos para produção de pectinases por diferentes linhagens de Aspergillus niger. Atualmente, existem diversas técnicas utilizadas para aumentar a produção de pectina liase por fungos filamentosos, entre elas a obtenção de cepas recombinantes contendo em seu material genético cópias adicionais do gene referente à produção dessa enzima (GONÇALVES et al., 2012).

Para o $\mathrm{pH}$ ótimo de hidrólise a pectina liase proveniente de polpa de buriti apresentou maior atividade enzimática $0,76 \mathrm{U} \cdot \mathrm{mL}^{-1} \mathrm{em} \mathrm{pH} \mathrm{6}$, enquanto a pectina liase proveniente de polpa de maracujá teve maior atividade enzimática $2,00 \mathrm{U} \cdot \mathrm{mL}^{-1}$ em $\mathrm{pH}$ 3. Percebe-se que à medida que $\mathrm{o} \mathrm{pH}$ do meio aumenta a atividade enzimática diminui, mostrando que a pectina liase é mais ativa em faixas de $\mathrm{pH}$ ácido (Figura 2). 


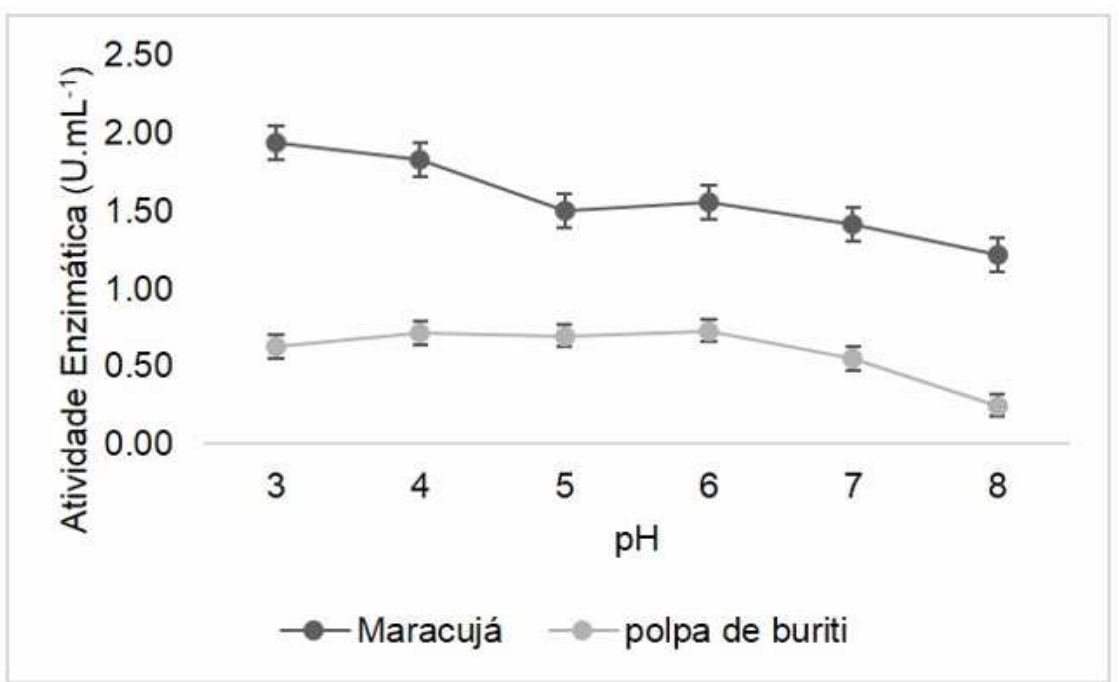

Figura 2 - Efeito do pH ótimo de hidrólise da pectina liase proveniente dos meios de cultivo em polpa de maracujá e de buriti.

A pectina liase proveniente de polpa de maracujá apresentou maior hidrólise em temperatura de $70^{\circ} \mathrm{C}$, com atividade pectina lias e de 7,76 U.mL $\mathrm{mL}^{-1}$, constatandose um declínio da atividade a partir dessa temperatura (Figura 3). Inversamente, a produção de pectina liase em polpa de buriti aumentou com a temperatura, alcançando 3,54 U.mL ${ }^{-1}$ a 80 ' C. A produção de pectina liase por Aspergillus oryzae observada por KOSER et al. (2014) foi máxima a $35^{\circ} \mathrm{C}$. Isso pode ser atribuído ao fato de que na fermentação em estado sólido temperaturas de incubação acima de $40{ }^{\circ} \mathrm{C}$ resultarem em perda de umidade do substrato, afetando a atividade metabólica do micro-organismo e, consequentemente, a produção enzimática (KOSER et al., 2014).

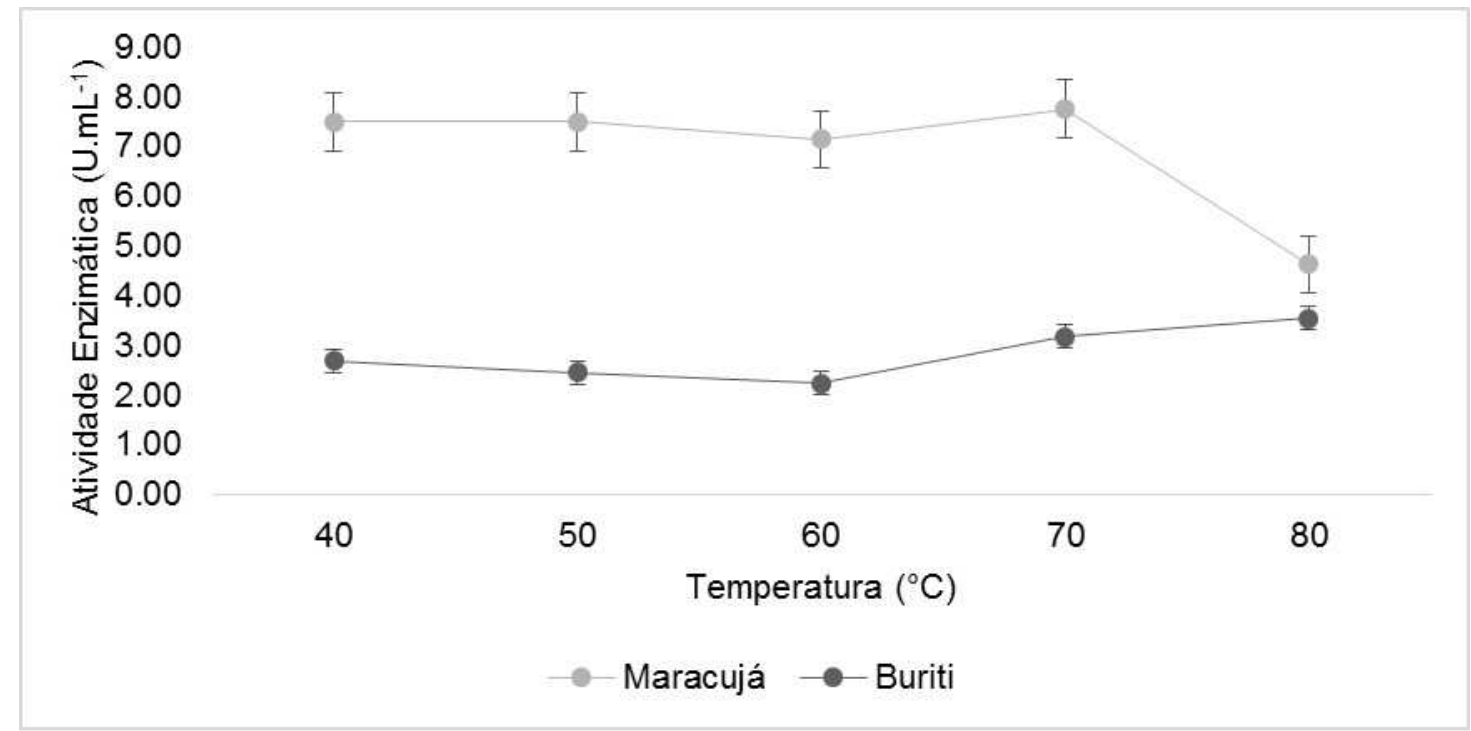

Figura 3 - Termohidrólise de pectina liase em meio de cultivo contendo polpa de maracujá e polpa de buriti como fontes de carbono.

Os resultados referentes à termoestabilidade mostram que após 30 min de incubação a enzima diminui a atividade nas temperaturas avaliadas para ambas as fontes (Figura 4). PEDROLLI \& CARMONA (2014), trabalhando com pectina liase 
purificada mostraram que a enzima consegue manter atividade a $40{ }^{\circ} \mathrm{C}$ durante 15 min, portanto inferior ao constatado nesse estudo.
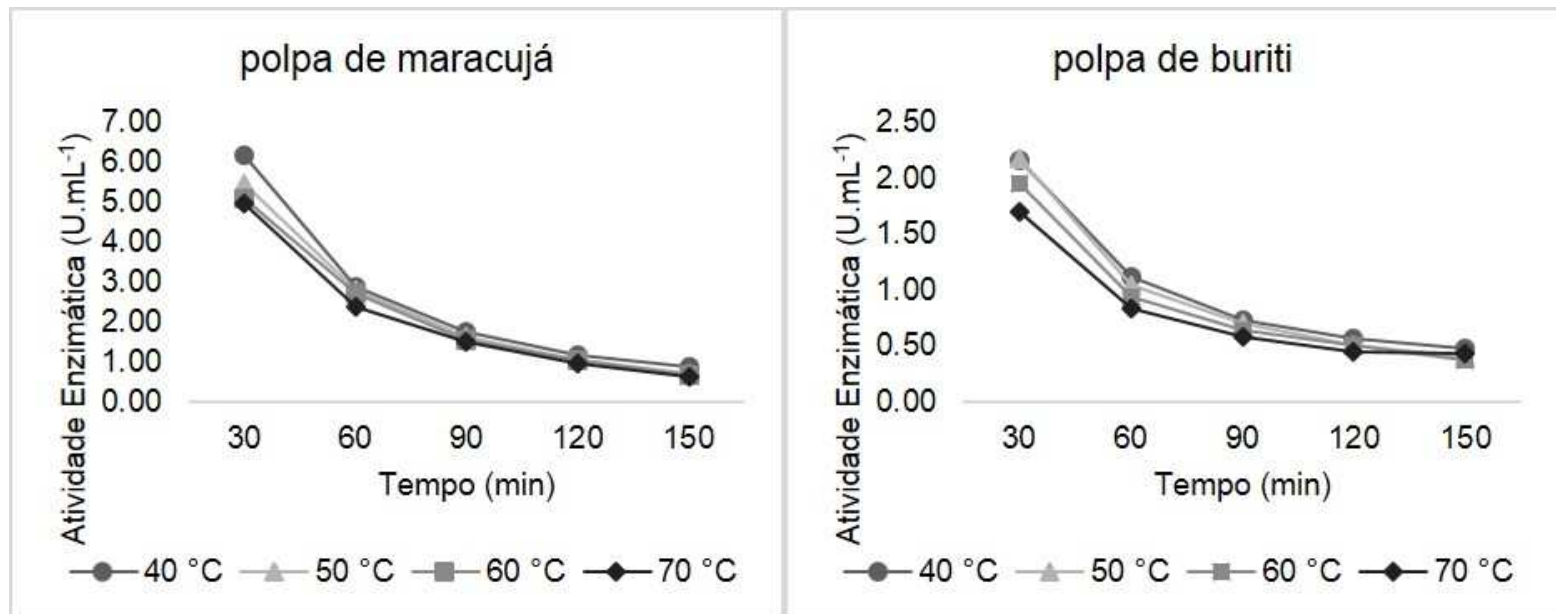

Figura 4 - Termoestabilidade de pectina liase em meio de cultivo contendo polpa de maracujá e polpa de buriti como fontes de carbono.

A pectina liase apresentou comportamento bioquímico diferente para cada fonte de carbono avaliada. As fontes de carbono avaliadas embora tenham características gerais semelhantes, cada enzima e cada micro-organismo possui suas peculiaridades e especificidades à hidrólise. Entretanto, segundo KOSER et al. (2014), além dos fatores externos, a composição físico-química do substrato também interfere na atividade enzimática.

\section{CONCLUSÃO}

A linhagem 2 mostrou-se mais promissora para a produção de pectina liase na presença da fonte de carbono polpa de buriti. A enzima proveniente da fonte de carbono polpa de maracujá apresentou maior atividade em pH 3. A mesma enzima manteve atividade enzimática estável quando incubada em temperaturas na faixa de 40 a $70{ }^{\circ} \mathrm{C}$. As enzimas provenientes das duas fontes de carbono apresentaram atividade enzimática após 30 min de exposição na temperatura de $70{ }^{\circ} \mathrm{C}$.

\section{REFERÊNCIAS}

ALBERSHEIM, P.; KILLIAS, U. Studies relating to the purification and properties of pectin transeliminase. Archives of Biochemistry and Biophysics, v.97, n.1, p.107$115,1962$.

BUENO, M. C.; PERES, M. F. S.; GATTÁS, E. A. L. Produção de poligalacturonase por três linhagens de Aspergillus isolados do solo. Alimentos e Nutrição, v.16, n.3, p. 253-257, 2005.

CAMARGO, L. A.; DENTILLO, D.B.; CARDELLO, L.; GATTÁS, E.A.L. Utilization of orange bagasse in pectinases production by Aspergilllus sp. Alimentos e Nutrição, v.16, n.2, p.153-156, 2005.

FRIEDRICH, J.; CIMERAMN, A.; STEINER, W. Concomitant synthesis of Aspergillus niger pectolytic enzymes and citric acid on sucrose. Enzyme and Microbial Technology, v.16, n.8, p.703-707, 1994. 
GERHARDT, J. A.; CARVALHO, I. F.; SILVA, M. L.; POLIZELI, M. L. T. M.; ALNOCH, R. C. Avaliação da atividade celulolítica de fungos filamentosos isolados de amostras de solo da região norte do estado de Mato Grosso. Enciclopédia Biosfera, v.11, n.21, p.1971-1981, 2015.

GONCCALVES, D. B.; TEIXEIRA, J. A.; BAZZOLLI, D. M. S.; QUEIROZ, M. V; ARAUUJO, E. F. Use of response surface methodology to optimize production of pectinases by recombinant Penicillium griseoroseum T20. Biocatalysis and Agricultural Biotechnology, v.1, n.2, p.140-146, 2012.

IRSHAD, M.; ANWAR, Z.; MAHMOOD, Z.; AQIL, T.; MAHMOOD, S.; NAWAZ, H. Bio-processing of agro-industrial waste orange peel for induced production of pectinase by Trichoderma viridi; its purification and characterization. Turkish Journal of Biochemistry, v.39, n.1, p.9-18, 2014.

KOSER, S.; ANWAR, Z.; IQBAL, Z.; ANJUM, A.; AQIL, T.; MEHMOOD, S.; IRSHAD, M. Utilization of Aspergillus oryzae to produce pectin lyase from various agroindustrial residues. Journal of Radiation Research and Applied Sciences, v.7, n.3, p.327-332, 2014.

MARTOS, M. A.; ZUBRESKI, E. R.; GARRO, O. A.; HOURS, R. A. Production of pectinolytic enzymes by the yeast Wickerhanomyces anomalus Isolated from Citrus Fruits Peels. Biotechnology Research International, v.2013, n.2, p.1-7, 2013.

OLIVEIRA, T. O.; PIMENTA, C. J.; CARDOSO, P. G.; SOUZA, S. M. C.; FABRÍCIO, L. F. F.; LEAL, R. S. Produção de pectina liase por isolados de cladosporium cladosporioides utilizando fermentação submersa e casca de uva como substrato. Higiene Alimentar, v.25, p.217-218, 2011.

PATIL, S. R.; DAYANAND, A. Production of pectinase from deseeded sunflower head by Aspergillus niger in submerged and solid-state conditions. Bioresour. Technol., v. 97, p. 2054-2058, 2006.

PEDROLLI, D. B.; CARMONA, E. C. Purification and Characterization of a Unique Pectin Lyase from Aspergillus giganteus Able to Release Unsaturated Monogalacturonate during Pectin Degradation. Enzyme Research, v.2014, p.1-7, 2014.

SAMPAIO, M. B. Boas práticas de manejo para o extrativismo sustentável do buriti. Brasília: Instituto Sociedade, 2011. 84p.

SANTI, L.; BERGER, M.; SILVA, W. O. B. da. Pectinases e pectina: aplicação comercial e potencial biotecnológico. Caderno pedagógico, v.11, n.1, p.130-139, 2014.

SANTI, L.; Produção, caracterização e aplicação de preparados pectinolíticos produzidos por Penicillium oxalicum utilizando resíduos agroindustriais. Dissertação de mestrado. UFRGS, Porto Alegre, 2005. 
SILVA, N. da; JUNQUEIRA, V. C. A.; SILVEIRA, N. F. A.; TANIWAKI, N. H.; SANTOS, R. F. S. dos; GOMES, R. A. R. Manual de Métodos de Análise Microbiológica de Alimentos e Água. ed. 4. São Paulo: Varela, 2010.

SIROTEK, K.; MAROUNEK, M.; RADA, V.; BENDA, V. Isolation and characterization of rabbit caecal pectinolytic bactéria. Folia Microbiol, v.46, n.1, p.79-82, 2001.

UENOJO, M.; PASTORE, G. M. Isolamento e Seleção de Microrganismos pectinolíticos a partir de resíduos agroindustriais para produção de aromas de frutas. Ciência e Tecnologia de Alimentos, v.26, n.3, p.509-515, 2006.

UENOJO, M.; PASTORE, G. M. Pectinases: Aplicações industriais e perspectivas. Química Nova, v.30, n.2, p.388-394, 2007. 